\title{
Sugars and Starches in a Non-Sweet Sweet Potato Compared to those of Conventional Cultivars $^{1}$
}

\author{
Franklin W. Martin and Shreekant N. Deshpande ${ }^{2}$
}

\begin{abstract}
Sweet potatoes that varied from a typical high sugar dessert through various degrees of sweet tropical type, and a new type of non-sweet staple were cooked by three methods, and sugar contents were compared with controls. Starch grain size was measured, and percent amylose was determined. Reducing power and intrinsic viscosity of extracted starches were determined to estimate molecular size and possible structure. Reducing sugar content increased on cooking except in one cultivar, the staple type "Ninety-nine". Low reducing power and high intrinsic viscosity might be indicative of a large, unbranched starch molecule.
\end{abstract}

\section{INTRODUCTION}

When sweet potato is cooked its sweetness increases (4). Increase in reducing sugars can be dramatic, and can lead to a very sweet, desserttype dish even without the addition of further sugar. Orange fleshed, very sweet roots are the preferred sweet potatoes of the temperate zone.

In the tropics, however, less sugary sweet potatoes are preferred as staples. Searches for such types have revealed clones with as little as $6 \%$ total sugar (1). Nevertheless, as emphasized by Palmer (8), the only meaningful measurements of sugar content for human consumption are those made after cooking. Therefore, development of staple type sweet potatoes depends on finding types with low sugar content even after conventional cooking.

The first low sugar types, produced by selection among seedlings of introduced germplasm as well as our own lines, are now on hand. The sugar content of these cultivars, even after cooking, appears to be at the threshold level for taste, or below. These also tend to have a dry mouthfeel, and may or may not contain $\beta$-carotene.

For this study we have compared the content of reducing, non-reducing and total sugars that occur in seven cultivars of sweet potato uncooked or cooked by three methods. These cultivars range from a typical dessert through tropical types of varying sweetness to a staple tropical type. We have also considered the characteristics of the starches, including amylose content, starch granule size, reducing power, and viscosity.

${ }^{1}$ Manuscript submitted to Editorial Board June 29, 1984.

${ }^{2}$ Research Horticulturist, United States Department of Agriculture, Science and Education, Agricultural Research Service, Southern Region, Tropical Agriculture Research Station, Mayagüez, Puerto Rico 00709; and Professor, Department of Chemistry, University of Puerto Rico, Mayagüez Campus, Mayagüez, Puerto Rico 00709. 


\section{MATERIALS AND METHODS}

The seven sweet potato cultivars used were Gem, a moist, orange fleshed cultivar from the United States; Miguela, a less sweet, white, native selection from Puerto Rico; Trompo Negro, a dense, somewhat sweet purple fleshed type; Frita and Spud, white staple type cultivars with still less sweetness; Papota, which, on the basis of sweetness, we consider substaple; and Ninety-nine, a non-sweet, white, dry-fleshed cultivar. Uniform storage roots of about $200 \mathrm{~g}$ were selected from freshly harvested sweet potatoes and treated as follows: uncooked controls were peeled, sliced and dried in a forced draft oven at $60^{\circ} \mathrm{C}$ for approximately 20 hours. For boiling, the roots were cut into cubes of $2.5 \mathrm{~cm}$., boiled 18 minutes, sliced, and dried. For conventional baking the roots were held in an oven at $220^{\circ} \mathrm{C}$ for 1 hour, sliced, and dried. For microwave baking the roots were held at maximum power for 5 minutes, and then sliced and dried. All cooking treatments resulted in a tender, attractive, cooked sweet potato. Dried samples were ground, sieved, and then tested for reducing, non-reducing, and total sugars by methods of AOAC used for dry flours (6). Each test was made in duplicate.

Starches were extracted by blending $50 \mathrm{~g}$ frozen, thawed, sweet potato with $200 \mathrm{ml}$ of distilled water for $3 \mathrm{~min}$., and by centrifuging at intermediate velocity for 8 minutes. The centrifugate was mixed with water and re-centrifuged three times. The starch was then dried in the centrifuge tube at $45^{\circ}$ for 12 hours. The average size of the starch grains was determined by measuring the diameter of 25 grains. Percent amylose of the starch was determined by the method of Gilbert and Spragg (5).

To characterize the starches with respect to their molecular weights and sizes, rapid methods of end group analysis (10) were used. The reducing power of end groups were determined by the dinitrosalicylic acid method as a possible indicator of the branching of the polymers. An amount of starch (50-60 mg) approximately equivalent in its reducing power to 200-400 micrograms of maltose was placed in $15 \times 2 \mathrm{~cm}$ test tubes. Ten milliliters of the alkaline 2,3-dinitrosalicylic acid reagent was added and dispersed thoroughly by mixing. The mixture was heated for 30 minutes at $100^{\circ} \mathrm{C}$, cooled, and volume adjusted to $25 \mathrm{ml}$ in volumetric flasks with distilled water. Light absorption was measured at 500 millicrons and concentrations were expressed as micrograms of maltose equivalent per $100 \mathrm{mg}$ of the starch sample.

The intrinsic viscosities of starch solutions were determined as an estimate of their weight-average molecular weights (7). A $0.5 \%$ stock solution was prepared by dispersing the starch in 0.155 molar $\mathrm{NaCl}$ in $0.2 \%$ disodium salt of ethylenediaminetetraacetic acid (EDTA), to overcome the charge effects, which otherwise lead to kinking and aggregation 
of polymers. The stock solutions were further diluted to $0.2,0.16$, and $0.1 \%$ by addition of the $\mathrm{NaCl}$, EDTA solutions, and their $\mathrm{pH}$ was adjusted to 6.5. The viscosities of these solutions were determined by means of a number 100, Ostwald-Finske ${ }^{3}$ viscometer. The intrinsic viscosities (ni) of the samples were determined by plotting $n \mathrm{sp} / \mathrm{c}$ values against the concentration values. The $\mathrm{Y}$ intercept thus yielded the intrinsic viscosity.

\section{RESULTS}

Measurements of reducing, non-reducing and total sugars are given in table 1 . They show clearly that there are strong differences in the sugar

TABLE 1.-Sugar content of roots of 7 sweet potato cultivars as influenced by cooking technique (mg/100 g dry weight)

\begin{tabular}{llrrrr}
\hline \multirow{2}{*}{ Sweet potato } & $\begin{array}{c}\text { Type of } \\
\text { sugar }\end{array}$ & Control & Boiling & $\begin{array}{c}\text { Conventional } \\
\text { baking }\end{array}$ & $\begin{array}{c}\text { Microwave } \\
\text { baking }\end{array}$ \\
\hline \multirow{2}{*}{ Gem } & Red. ${ }^{1}$ & $7.68^{2}$ & 23.42 & 33.10 & 25.60 \\
Miguela & N. Red. & 15.90 & 10.60 & 12.30 & 10.10 \\
\multirow{2}{*}{ Trompo Negro } & Red. & 3.25 & 18.65 & 18.55 & 22.08 \\
& N. Red. & 8.10 & 5.20 & 9.50 & 7.10 \\
Frita & Red. & 2.50 & 21.80 & 19.80 & 22.10 \\
\multirow{3}{*}{ Spud } & N. Red. & 9.50 & 8.25 & 9.75 & 8.60 \\
& Red. & 2.80 & 21.00 & 30.80 & 15.6 \\
Papota & N. Red. & 10.40 & 8.90 & 10.00 & 10.2 \\
& Red. & 4.60 & 18.80 & 25.10 & 14.00 \\
Ninety-nine & N. Red. & 7.90 & 7.10 & 7.90 & 7.60 \\
& Red. & 2.42 & 5.25 & 7.05 & 6.85 \\
& N. Red. & 6.75 & 5.40 & 6.50 & 6.55 \\
& Red. & 0.82 & 0.82 & 0.88 & 0.77 \\
& N. Red. & 5.45 & 4.05 & 4.55 & 5.70 \\
\hline
\end{tabular}

${ }^{1}$ Red. = Reducing sugar, N. Red. = Non-reducing sugars.

${ }^{2}$ Average of two measurements.

contents of uncooked sweet potatoes. Total sugars varied from 6.3 to $23.6 \%$. In all cultivars the percentage of non-reducing sugars was higher than that of reducing sugars.

Cooking increased the reducing sugar content of 6 cultivars. The amount of non-reducing sugars was not increased by cooking. The different cooking techniques were similar in effects on sugar content. However, boiling tended to slightly reduce contents of non-reducing sugars, most likely through leaching. Since leaching as well as starch

\footnotetext{
${ }^{3}$ Trade rarnes in this publication are used only to provide specific information. Mention of a trade name does not constitute a warranty of equipment or materials by the Agricultural Experiment Station of the University of Puerto Rico, nor is this mention a statement of preference over other equipment or materials.
} 
hydrolysis apparently occurred during boiling the final content of reducing sugars was somewhat less than that after baking. Conventional baking, lasting an hour, usually produced more reducing sugars than microwave baking, lasting 5 minutes. In the orange moist cultivar Gem, conventional baking resulted in a total sugar content of $45 \%$. The typical sweet tropical cultivars Miguela and Trompo Negro also were quite sweet after cooking. The cultivars Frita and Spud were selected for less sweetness, yet they were still sweet after cooking. In the cultivar Papota, sugars increased only slightly on cooking. Sugars were not increased by cooking in the cultivar Ninety-nine.

Starch grains (table 2) ranged in average size from 0.057 to $0.080 \mathrm{~mm}$ in diameter. Differences in starch size were not associated with sweetness. Percent amylose varied from 27 to 38 percent. The starch of the most sugary sweet potato, Gem, contained a much higher percentage of amy-

TABLE 2.- Size of starch granule and percent amylose in sweet potatoes

\begin{tabular}{lcc}
\hline \multicolumn{1}{c}{ Cultivar } & $\begin{array}{c}\text { Size of starch } \\
\text { grain }\end{array}$ & Amylose \\
\hline Gem & $\mathrm{mm}$ & $\%$ \\
Miguela & 0.080 & 38 \\
Trompo Negro & .058 & 28 \\
Frita & .057 & 27 \\
Spud & .060 & 29 \\
Papota & .062 & 30 \\
Ninety-nine & .058 & 28 \\
& .059 & 29 \\
\hline
\end{tabular}

lose than starches of other cultivars. However, the amount of amylose in the non-sweet Ninety-nine was not lower than average.

The result of end group analysis revealed surprising differences among the starch samples with respect to reducing power (table 3). The cultivar Papota was highest in this respect, and the cultivar Ninety-nine was lowest. The reducing power of the starches was apparently not correlated with sugar content of the cultivar.

If reducing power of the starch is accepted as a measure of the number of end groups of starch molecules, then Ninety-nine, that cultivar which was not sweet after cooking, had the least number of end groups. Such low reducing power could be due to very large, relatively unbranched molecules with relatively few end groups.

With respect to intrinsic viscosity, Papota and Frita had the lowest (table 3) and Spud and Ninety-nine the highest. The great range in viscosities suggests a very great range among cultivars in starch molecule size. 


\section{DISCUSSION}

It is now apparent that sweet potatoes vary not only in their sugar contents at harvest but also after cooking, for during cooking the starch is broken into sugars and dextrins (9). The amount of amylose versus amylopectin, as measured by iodimetric techniques, and the starch grain size, as measured under the microscope, do not give any indication of the causes of these differences.

However, data from the reducing power analysis and intrinsic viscosities permit a tentative interpretation at this time. The starches of Frita and Papota with low intrinsic viscosities and high reducing powers may have low molecular weights and highly branched polymers for their constituent polysaccharides.

The starch of Spud with a relatively high viscosity and a high reducing power appears to have a high molecular weight and a highly branched polymer.

TABLE 3.-Reducing power and intrinsic viscosities of starches of seven sweet potato culivars

\begin{tabular}{lcc}
\hline \multicolumn{1}{c}{ Cultivar } & Reducing power $^{\mathbf{1}}$ & Intrinsic viscosity $^{2}$ \\
\hline Gem & 109 & 18.7 \\
Miguela & 368 & 16.8 \\
Trompo Negro & 91 & 15.2 \\
Frita & 356 & 8.8 \\
Spud & 308 & 22.8 \\
Papota & 482 & 11.5 \\
Ninety-nine & 77 & 21.8 \\
\hline
\end{tabular}

${ }^{1} \mathrm{Mg} / 100 \mathrm{~g}$ maltose equivalent.

${ }^{2}$ Units of $\eta \mathrm{i}$.

Most important to us, however, is the interpretation of the starch of Ninety-nine, the only cultivar described so far that is not sweet after cooking. The high viscosity of this cultivar as well as its low reducing power suggests a large, relatively unbranched polymer.

The question might arise if the relatively great differences in reducing power and intrinsic viscosities could have been caused by other factors than differences in the starch themselves. The technique used for starch extraction, washing and setting out, in this case aided by centrifugation, cannot produce an absolutely pure starch, even though the three washings can be expected to have removed virtually all water soluble and low density substances. We find, however, that our precautions have been equal or greater than those usually taken for the production and study of the properties, including viscosity of starches $(2,3,9,11)$. The effect of cooking on mouthfeel, closely related to viscosity, may be related either to pectic substances (2) or to starch fractions (11) in the whole, cooked 
root. The question of type of starch molecule merits reexamination when more staple type cultivars have been produced.

The cultivar Ninety-nine appears to combine, to the highest degree that we have yet seen, the characteristics desired in a staple type sweet potato. Not only is the sugar content low in the uncooked root, but also cooking does not increase the sugar content. When boiled and mashed this sweet potato can be eaten every day as a staple food. Since we are now finding other sweet potatoes of this type, we consider this cultivar a prototype of the kinds of staple sweet potatoes that can be developed.

\section{RESUMEN}

Se midieron los azúcares reductores y no reductores de siete cultivares de batatas que variaron en dulzura. Al cocinar estas batatas las cantidades de azúcares reductores aumentaron en seis de las siete cultivares y las de azúcares no reductores se quedaron igual o disminuyeron un poco. La inspección del tamaño de las partículas de almidón o contenido de amilosa no ayudó a explicar la variedad no dulce, "Ninety-nine". Sin embargo, al medir el poder reductivo del almidón mismo y su viscosidad intrínseca se encontró la sugerencia de que tal cultivar tenga una molécula grande y poco ramificada. Este cultivar sirve como prototipo de una clase nueva de batatas gue se está desarrollondo, baja en dulzura y apropiada para comer todos los días.

\section{LITERATURE CITED}

1. Asian Vegetable Research and Development Center, 1982. Prog. Rep. for 1980, Shanhua, Taiwan.

2. Baumgardner, R. A. and L. E. Scott. 1963. The relation of pectic substances to firmness of processed sweet potatoes, Proc. Am. Soc. Hort. Sci. 83: 629-40.

3. Bertoniere, N. R., T. A. McLemore, V. C. Hasling, E. A. Catalano, and H. J. Deobald. 1966. The effect of environmental variables on the processing of sweet potatoes into flakes and on some properties of their isolated starches. Food Sci. 31: 574-81.

4. Edmond, J. B., 1971. Sweet potatoes. Production, Processing, Marketing. AVI Publishing Co., Westport, Connecticut.

5. Gilbert, G. A. and S. P. Spragg. 1964. Methods of Carbohydrate Chemistry, Vol. IV. Academic Press, New York.

6. Horowitz, W., 1980. Official Methods of Analysis. Association of Official Analytical Chemists, 13th ed, Washington, D.C.

7. Owens, H. S., H. Lotzkar, T. H. Schultz and W. D. Maclay. 1946. Shape and size of pectinic acid molecules, deduced from viscometric measurements, J. Am. Chem. Soc. 68: 1628-632.

8. Palmer, J. W., 1983. Carbohydrates of Sweet Potato, pp. 135-140. In: Villareal, R. L. \& T. D. Griggs, (Ed). Sweet Potato, Proc. First Int. Symp., Asian Vegetable Research and Development Center, Shanhua, Tainan, Taiwan.

9. Shen, M. C. and D. C. Sterling. 1981. Changes in starch and other carbohydrates in baking Ipomoea batatas. Starch/Stärke 33: 261-68.

10. Smith, F. and R. Montgomery. 1956. End group analysis of polysaccharides. In: Methods of biochemical analysis of polysaccharides, D. Glick (Ed), Inter. Sc., New York, 8 V.

11. Walter, W. M., Jr., A. E. Purcell and A. M. Nelson. 1975. Effects of amylolytic enzymes on "moistness" and carbohydrate changes of baked sweet potato cultivars. J. Food Sci. 40: 793. 